\title{
Activity-specific mobility of adults in a rural region of western Kenya
}

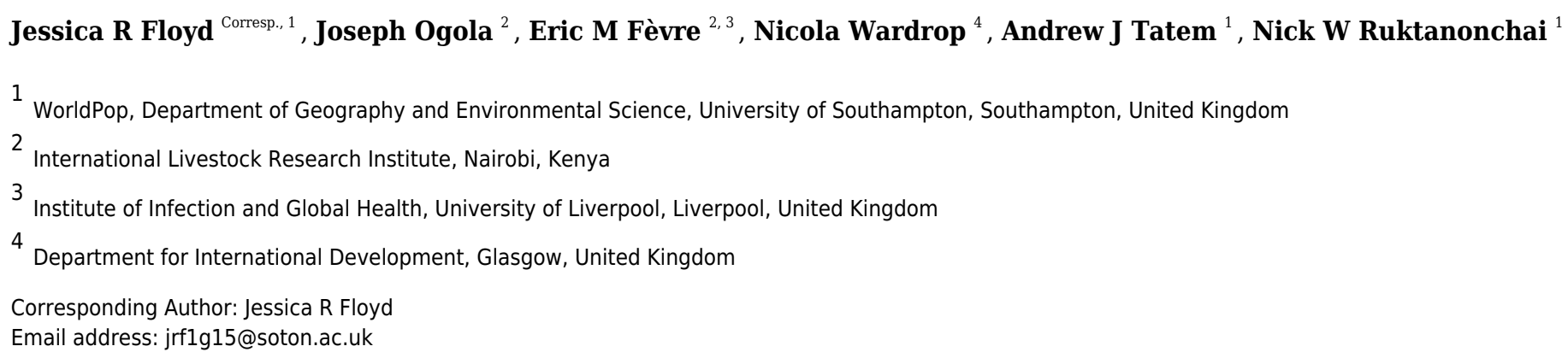

Improving rural household access to resources such as markets, schools and healthcare can help alleviate poverty in low-income settings. Current models of geographic accessibility to various resources rarely take individual variation into account due to a lack of appropriate data, yet understanding mobility at an individual level is key to knowing how people access their local resources. Our study used both an activity-specific survey and GPS trackers to evaluate how adults in a rural area of western Kenya accessed resources in their local area. We calculated the travel time and time spent at six different types of resource and compared the GPS and survey data to see how well they matched. We found links between several demographic characteristics and the time spent at different resources, and that the GPS data reflected the survey data well for time spent at some types of resource, but poorly for others. We conclude that demography and activity are important drivers of mobility, and a better understanding of individual variation in mobility could be obtained through the use of GPS trackers on a wider scale. 


\section{Activity-specific mobility of adults in a rural region of 2 western Kenya}

3

4

5 Jessica R. Floyd ${ }^{1}$, Joseph Ogola ${ }^{2}$, Eric M. Fèvre ${ }^{2,3}$, Nicola Wardrop ${ }^{4}$, Andrew J. Tatem ${ }^{1}$, Nick W.

6 Ruktanonchai $^{1}$

7

8

9

14 Corresponding Author:

15 Jessica R. Floyd ${ }^{1}$

16 University Road, Southampton, SO17 1BJ, UK

17 Email address: jrf1g15@soton.ac.uk

${ }^{1}$ WorldPop, Department of Geography and Environmental Science, University of Southampton, Southampton, UK

${ }^{2}$ International Livestock Research Institute, Nairobi, Kenya

${ }^{3}$ Institute of Infection and Global Health, University of Liverpool, UK

${ }^{4}$ Department for International Development, Glasgow, UK

8

19 


\section{Abstract}

21 Improving rural household access to resources such as markets, schools and healthcare can help

22

23

24

25

26

27

28

29

30

31

32

33

34

35

36

37

38

39

40

41

42

43

44

45

46

47

48

49

50

51

52

53

54

55

56

57

58

59

alleviate poverty in low-income settings. Current models of geographic accessibility to various resources rarely take individual variation into account due to a lack of appropriate data, yet understanding mobility at an individual level is key to knowing how people access their local resources. Our study used both an activity-specific survey and GPS trackers to evaluate how adults in a rural area of western Kenya accessed resources in their local area. We calculated the travel time and time spent at six different types of resource and compared the GPS and survey data to see how well they matched. We found links between several demographic characteristics and the time spent at different resources, and that the GPS data reflected the survey data well for time spent at some types of resource, but poorly for others. We conclude that demography and activity are important drivers of mobility, and a better understanding of individual variation in mobility could be obtained through the use of GPS trackers on a wider scale.

\section{Introduction}

Population mobility is a complex process with great importance in many fields across the social and health sciences(1-3). Often, people travel because of specific resource needs or activities such as gathering food and water, livelihood and occupational activities, or accessing healthcare. In low-income settings, travel to these resources can be very time-consuming or expensive meaning that people may forego healthcare, employment, or other resources. As a result, the geographic inaccessibility of vulnerable populations can lead to worse health outcomes, a poorer economic outlook, and can widen spatial inequalities(4-6). In Kenya, resource access is particularly important for poverty reduction in rural populations, as people often have to travel further for resource-related activities than their urban counterparts. It is widely accepted that people in rural areas spend more time accessing resources than people in urban areas, and that this likely contributes to poverty in these areas. For example, market access is important for several household activities such as gathering food, selling crop surpluses and buying medicine, and studies have shown that poor market access contributes to poverty in rural areas(7). Similarly, poor water source access means reduced time for making money elsewhere and therefore contributes to household poverty, as well as being linked to poor health $(8,9)$.

Geographic inaccessibility of healthcare is also a known driver of poor health outcomes, particularly in rural settings $(10,11)$. Government policies in Kenya have responded accordingly, through measures designed to ensure that everyone lives within $5 \mathrm{~km}$ of basic healthcare services. In 2003 it was estimated that $82 \%$ of the population live within $5 \mathrm{~km}$ of a primary healthcare and referral service(12). Because geographic accessibility is vitally important for ensuring vulnerable populations can utilise healthcare, a significant body of recent research focuses on modelling accessibility across national scales. Often, these accessibility models assume that people visit their nearest clinic(13), using accessibility surfaces or straight-line distances to predict clinics used and associated travel times. In reality, geographic accessibility remains highly heterogenous

Peer) reviewing PDF | (2019:06:38955:1:2:NEW 16 Jan 2020) 
60

61

62

63

64

65

66

67

68

69

70

71

72

73

74

75

76

77

78

79

80

81

82

83

84

85

86

87

88

89

90

91

92

93

94

95

96

97

98

99

across the country despite new clinics in resource-poor areas(14), and straight-line distance is not the only factor that impacts whether people can access healthcare in a reasonable time without undue expense. Other factors such as poor road quality and lack of public transport options can severely impact mobility and therefore healthcare access in rural areas where the most vulnerable populations live $(15,16)$. In Kenya, recent studies have found that people often visit clinics other than their nearest one, for reasons such as the availability of medicines or the perceived effectiveness of the facility(17). One study found that only $54-63 \%$ of people surveyed visited their nearest facility, with the rest visiting other clinics(18).

Moreover, resource-related movement is quantitatively different from other types of mobility, so accessibility models that predict general mobility patterns may not accurately reflect resource seeking behaviour. For example, a recent study in Iquitos, Peru found that residents moved significantly further for commercial and familial reasons than for healthcare(19).

Sociodemographic factors could also influence mobility and resource-specific movement: household income, rural/urban context(20) and gender are all important determinants of mobility, but spatial models of access often lack this demographic information, assuming that all adults access resources such as markets and health facilities identically, regardless of socioeconomic context. More detailed movement datasets could help improve these models by providing evidence to support or reject these key assumptions and better understand how movements driven by different activities vary.

Additionally, mobility studies typically focus on single types of resource access without comparing against travel of other types(21),(22), particularly in a rural context where activitydependent mobility models could provide a richer picture of how people spend their time, and how resource-specific movement could exaggerate or mitigate geographic inaccessibility. Traditionally, studies of individual mobility have relied on survey methods, which may be affected by recall bias(23). In recent years, specialised tools such as personal Global Positioning System (GPS) tracking devices employed at a household level have facilitated the collection of detailed movement information(24-26). Personal GPS trackers have been used in urban and rural settings to document the movements of both humans and animals in a variety of contexts, from investigating the diving behaviour of certain species of birds $(27,28)$ to the social structures of cattle in pastoral communities(29) to detailed human movements in urban settings(25). With good portability, weight and battery life, this type of tracker has also been used in research into healthcare access(30) and vector-borne disease $(24,25)$. Given the growing populations in rural areas of lower-income countries, detailed knowledge of activity spaces and health facility access in a rural context could have benefits for better understanding specific types of resource access.

Here, we use surveys of people in a rural area of western Kenya to capture movements to and time spent on different types of activity, and examine links between these and demographic characteristics. We use GPS trackers to explore where the same people spent their time outside 
100

101

102

103

104

105

106

107

108

109

110

111

112

113

114

115

116

117

118

119

120

121

122

123

124

125

126

127

128

129

130

131

132

133

134

135

136

137

138

139

of their households. We then compare these two sources of data to see how well they capture proportions of time spent on different types of activity. . The results from this study shed light on the activity spaces of people in relation to resource access in a resource-poor setting and provide evidence for how well GPS trackers are able to capture daily activities compared to survey methods. They also help quantify the importance of including sociodemographic and activityspecific movement into geographic accessibility models, particularly for healthcare infrastructure.

\section{Materials \& Methods}

\section{Study area and population}

This study was conducted in the densely populated county of Busia in the Lake Victoria basin region of western Kenya (Fig. 1). Busia county has a population of just under one million people(31), of whom approximately $80 \%$ live in rural areas (as defined by the latest DHS survey) and practice smallholder subsistence farming, mainly operating mixed crop-livestock systems with $60 \%$ of households in rural areas owning cattle(32).

We used a clustered random sampling strategy to select 55 households to visit and survey in Busia county. Of the 181 sublocations in the county, 11 were selected at random and within these we selected five households for participation in the study, by randomly generating coordinates within each sublocation, and choosing the household closest to each of the coordinates, up to 200 metres. A surplus of coordinates (up to ten) were generated in each sublocation, so that if a household could not be identified within 200 metres, the next set of coordinates were used. We used QGIS software tools(33) for the random selection of sublocations and coordinates. Due to the lack of appropriate data to base a sample size calculation on, we chose to sample 55 households from a broad geographical range based on the manpower and time available for fieldwork while optimising the use of the limited number of GPS trackers. We selected 30 of the 55 households for GPS tracking because this was the maximum number of people that could be tracked for a full week with the resources available.

Households were selected if they were the main residence of at least one consenting adult present at the time of the visit. Inclusion criteria for participation were consenting adults aged 18 years or over who were present at the time of the visit. Some demographic characteristics of the study population are given in Table 1. If the household declined to participate in the study, the next household closest to the coordinates was visited. All adults within a household were selected for participation in the survey, but only the adult who spent most time looking after livestock (determined from survey responses and verbal discussion) was selected for participation in the GPS tracking. If the household had no livestock, the head of the household (determined by verbal communication) was selected instead. These choices enabled analysis of the activities of populations that spent time with livestock and therefore may be at higher risk of some zoonotic 
140 diseases. This limits the representativeness of the sample population, but we felt this was acceptable given the small sample size.

142

Data collection - survey

144

A structured survey with closed and open questions was administered to all consenting members aged 18 years or over present in the household at the time of visiting (see supplementary information). The survey included questions on demographic characteristics, regular movements outside of the household and activities involving livestock. For movements to places outside the household, we asked about the type of place visited (e.g. school, water source, place of worship, market etc.), how often the respondents visited, the mode of transport used and time spent travelling, and how long they usually spend there. The types of places were pre-defined based on information from previous studies in this area $(34,35)$, and the survey included open-ended questions to identify any other significant types of place. A village elder was present to facilitate introduction to the household and explanation of the study. The survey was written in English and administered through an interpreter. The survey included 10 closed-ended questions from the Poverty Probability Index for Kenya(36). The answers to these questions were scored to obtain a basic index of household wealth which was used to compare relative wealth between households. The answers to the survey, including collection of GPS coordinates to determine household location, were collected on a tablet using a custom-designed survey built with OpenDataKit $(\mathrm{ODK})(37)$ software and uploaded to a secure server once an internet connection could be

160

161

162

163

164

165

166

167

168

169

170

171

172

173

174

175

176

177

178 179 established.

\section{Data collection - GPS data}

During the same visit, the consenting participant was given a GPS tracker (i-gotU GT-600 by Mobile Action(38)) to wear for one week, fitted to a lanyard, which could be worn around the neck or carried in a pocket. We chose this length of time based on previous studies $(39,40)$ and to maximise the use of our limited number of GPS trackers. The time interval used on the trackers was one minute and the devices were programmed to power off if stationary for two minutes, then turn on again when movement was detected. At the end of the week, the researchers returned to the household to collect the trackers and download the data.

The data collection was conducted in two phases: household survey and GPS tracking in July/August 2016, followed by GPS tracking only in November/December 2016. In phase two, the same households were visited as in phase one and the GPS tracking was repeated with the same participants where possible, in order to capture potential differences in movement patterns during different seasons, henceforth called the short rainy season (July/August 2016) and the dry season (November/December 2016) in accordance with climate classifications for this region of Kenya(41). Of the 26 trackers given out in each season, one device was unrecoverable and two suffered battery issues during the week (these weeks were therefore repeated). 
180

181

182

183

184

185

186

187

188

189

190

191

192

193

194

195

196

197

198

199

200

201

202

203

204

205

206

207

208

209

210

211

212

213

214

215

216

217

218

219

\section{Data analysis}

The survey and GPS data were downloaded in .csv format, then cleaned and analysed using R version 3.1.1 software(42). Erroneous points in the GPS data were identified by their unlikely speeds and deleted using functions from the trip(43) package. A linear interpolation algorithm was then applied to obtain locations at regular intervals. Erroneous points can occur due to changing atmospheric conditions and building obstructions, and accounted for less than $1 \%$ of the dataset. We used survey response, GPS points collected in the field and publicly available datasets of health facilities (44) to group the places where people spent time into six categories: household or residential places;, shops and markets; places of worship; health facilities; places where livestock activities occurred; and places where activities related to water (but not livestock) occurred. A central GPS point was identified for each of the places, and a 25-metre radius around that point was used to determine when that place was visited by a person, defined as 5 minutes or more spent within that radius. Due to their larger size, a radius of 50 metres was used for market centres.

We conducted univariable analyses using linear mixed models for the three movement measures calculated from survey responses (frequency of visits, time spent travelling and time spent at places). We log transformed these data to ensure an approximately normal distribution and used linear models to examine their relationships with the covariates. Because of the hierarchical nature of the data (individuals nested in clusters, with repeat measurements per individual), we used linear mixed models (LMMs) which had the individual household nested within the sublocation as a random effect, to account for variation between individuals from different households and within different sublocations. Variables were chosen for analysis in line with those found to be important to movement metrics in previous studies in the area $(34,35,45)$.

\section{Ethics statement}

This study was approved by the Institutional Research Ethics Committee and the Institutional Animal Care and Use Committee of the International Livestock Research Institute (IDs: ILRIIREC2016-11; IACUC-RC2016-14; committees approved by the Kenya National Commission for Science, Technology and Innovation (NACOSTI)) and the Ethics and Research Governance board at the University of Southampton (ID:18984). All participants provided signed, informed consent for their participation in the study and the data were stored securely in accordance with the University of Southampton data storage policy.

\section{Results}

We used the survey data to explore where people spent most of their time, how long they took to get there and how long they stayed when visiting places outside of the household. When examining the places people travelled to regularly, we found substantial variation in the frequency of visits to different types of places compared to healthcare visits (Fig. 2). As 
220

221

222

223

224

225

226

227

228

229

230

231

232

233

234

235

236

237

238

239

240

241

242

243

244

245

246

247

248

249

250

251

252

253

254

255

256

257

258

259

260

expected, participants visited health facilities less often than other types of locations, the mode being three to six visits a year with very few visiting more often than monthly. Visits to areas where livestock activities occurred (such as grazing pastures) and to water sources were the most polarised out of all types of travel, with most visits occurring daily or not at all.

We asked participants about how long they spent travelling to different places and found that mean one-way travel times to health facilities ranged from 4 minutes to 2 hours. Participants reported spending the shortest time travelling when tending to livestock (median 9 minutes one way), and the longest times when visiting a market (median 34 minutes one way). We found the greatest range of travel times for visits to health facilities, markets and places of worship, while visits to livestock areas, water sources and other households tended to have shorter travelling times (Fig. 3).

We also asked about the amount of time people spent at different places. Participants reported spending the longest times at health facilities and places of worship (median 3 hours for both), and the shortest times at other households (median 45 minutes) and water sources (median 9 minutes). Figure 4 shows how the time spent by participants varied by type of place.

We used the three movement measures (frequency of visits, time spent travelling and time spent at places) and the demographic characteristics collected in the survey to conduct a univariable analysis to explore correlations (Table 2). We found that men reported spending more time at and making more frequent visits to places where livestock activities occurred compared to women $(p=0.017$ and $p=0.007$, respectively), while women reported spending more time at and making more frequent visits to health facilities than men did $(p=0.019$ and $p<0.001$, respectively). Women also made more frequent visits to water sources than men but did not spend significantly more time there $(\mathrm{p}=0.075)$. Older people tended to visit health facilities and water sources less often ( $p=0.041$ and $p<0.001$, respectively) and spend less time at places of worship ( $p=0.003$ ) than younger people. No significant relationships were observed between time spent travelling to places and any of the demographic characteristics tested; these results are reported in the supplementary information.

\section{GPS validation}

Lastly, we used the GPS data to explore the time participants spent outside of their households, and measure how variable overall movements were in our study population. We found that people spent between $5 \%$ and $52 \%$ of their time outside of their households over the week that they were tracked. For each GPS dataset, we were able to identify the type of place visited for between $2 \%$ and $97 \%$ of the time recorded outside of the household;some movements could not be characterised because not all locations in the local area were identifiable through the survey or mapping techniques. We selected GPS datasets where the season tracked was the same as when the survey was conducted and where over a third of minutes were identified, resulting in 27 GPS 
261

262

263

264

265

266

267

268

269

270

271

272

273

274

275

276

277

278

279

280

281

282

283

284

285

286

287

288

289

290

291

292

293

294

295

296

297

298

299

300

datasets with matching survey data. We compared these to explore how well the GPS data were able to mirror how people spent their time at different places. For this comparison, we only selected types of places that at least $50 \%$ of people with GPS data visited at least once a week, apart from the health facility locations, which we included for their public health importance. Unsurprisingly since not all GPS points could be identified, participants reported spending more time at all place types than captured by the GPS (hours reported in survey minus hours recorded by GPS was positive). In most cases, this difference was less than 1 hour of difference per day for each type of place.

Because the GPS data consistently underreported the absolute amount of time spent at different places compared to the survey data, we also compared how well the survey and GPS data were able to capture the proportions of time spent at the different place types. Figure 5 shows how GPS data found very similar proportions of time spent compared to those reported in the survey for some types of places, such as shops and places where livestock-related activities occurred. Other types of places had large differences in proportion of times spent between the two datasets - specifically, time spent at places of worship and visits to other households and health facilities. Using a paired t-test we found significant differences in the mean proportions of time spent at other households and places of worship ( $p=0.002$ and $p=0.041$, respectively) between the survey and GPS datasets. The GPS datasets recorded more trips to other households than recounted in the survey, while the survey had more trips to places of worship than recorded in the GPS, potentially due to a recall bias effect: people may be more likely to recall movements that they place higher intrinsic value on. There is also the possibility of a 'social desirability' bias: participants may be tempted to overstate the amount of time spent at more desirable locations such as places of worship, particularly as the survey was conducted in the presence of village elders.

\section{Discussion}

Geographic inaccessibility is a primary factor for many poor communities that are unable to easily use important infrastructure and natural resources, particularly in rural areas $(4,7,46)$. Even within these communities, accessibility can vary between individuals and can manifest differently when people are traveling for various types of resources(19,21). Better understanding of how accessibility varies with type of activity and with an individual's socioeconomic context could help inform future analyses on geographic accessibility. This socioeconomic and activitybased understanding of mobility can also help with identifying populations in communities at especially high risk of being unable to access healthcare and other services.

When comparing accessibility to a variety of resources we found that time people spent accessing different resources was not homogenous and had some links to demographic characteristics. Specifically, we observed that mobility related to livestock-related activities and health facilities were correlated with factors such as occupation, age and gender, while other 
301 types of activities like household visits and market visits were not. The small sample size and 302 bias towards rural households mean that the representativeness of these results is limited, but 303 nevertheless, combined with evidence of social differences in resource access from previous 304 studies in this area(47), they suggest further research into inequalities in resource access could be

305 306

307

308

309

310

311

312

313

314

315

316

317

318

319

320

321

322

323

324

325

326

327

328

329

330

331

332

333

334

335

336

337

338

339

340 beneficial for improving individual and thus population welfare.

Broadly, we also found that people access different resources with variable frequencies and spent varying amounts of time there. For example, people visited places where livestock-related activities occurred and water sources either frequently or not at all, while other types of places like health facilities and places of worship were visited by most participants on a regular basis. The time spent at each type of place also showed large variation, with people spending the longest times at health facilities and places of worship, and the shortest times at other households and water sources. These findings, while unsurprising, demonstrate a heterogeneity in resource access between individuals. Travel times to health facilities in our study were longer than to other types of places - a finding which differs from results in Iquitos, Peru, where people travelled less far for health reasons than for commercial and household reasons(19). This highlights how health facilities in rural communities such as our study area are likely more inaccessible than other resources when compared to access in an urban area such as Iquitos.

Notably, when comparing health facility visits and water source visits (two resources widely regarded as fundamental human rights), we observed that people spent longer both travelling to and at health facilities compared to water sources. However, travelling time to health facilities suggest that most people live within the government target of $5 \mathrm{~km}$ from a health facility, and previous evidence from rural Kenya found that travel time to health facilities did not affect child mortality in areas with many facilities(48), leading to calls for more focus on social determinants and quality of care and other factors that influence healthcare access and use. Our findings underscore this, as people reported having to spend a mean of 3 hours waiting at health facilities, compared to under 10 minutes to access water.

We also found some significant gender disparities in the amount of time people spent at different places, which could influence healthcare utilisation patterns. Men reported spending longer than women on livestock-related activities, while women spent longer than men at health facilities and water sources. Women reported visiting health facilities more frequently than men, possibly because they are usually responsible for their children's healthcare as well as their own(49). The differences in time spent by gender suggests that women are having to wait longer to access healthcare than their male counterparts. Previous studies in rural communities in Kenya and neighbouring Tanzania have found that waiting times, like time spent travelling to the facility, are a major barrier to accessing care and can result in delayed care-seeking behaviour, particularly for women due to the opportunity cost of accessing care over their domestic responsibilities(50-52). Since women both visit more often on behalf of their families and spend 
341 more time at health facilities, measures to reduce waiting times could have a direct benefit to

342 both their and their families' health.

343

344 Finally, we compared the travel times and frequencies reported in GPS and survey data, to

345

346

347

348

349

350

351

352

353

354

355

356

357

358

359

360

361

362

363

364

365

366

367

368

369

370

371

372

373

374

375

376

377

378

379

380 quantify potential biases in each and address the potential value of both datasets. The survey results are likely affected by recall bias and a social desirability bias. Notably, the GPS data were limited by the short data collection period and the small sample size, failing to capture visits to health facilities in the time available. Nevertheless, for places frequently visited during the data collection period, they more objectively reflected proportions of time spent compared to the survey data. Compared to surveys, GPS tracking technology could give a more complete picture of activity spaces in rural contexts, but require long data collection periods and a thorough knowledge of the local area. This knowledge could be obtained through a variety of methods, such as a participatory mapping approach, and could help to reduce recall bias effects. Future studies may be able to overcome the time and cost issues of increasing the data collection period by utilising smartphone technology, which already capture GPS locations of individuals under certain conditions. The collection of smartphone data in combination with GPS trackers has recently been piloted in an urban area of the UK and showed that location histories from smartphones can be valid datasets for exploring individual movements(53). In low-income areas of sub-Saharan Africa, this method would have a substantial bias towards wealthy people and is dependent on reliable cell phone network coverage, but smartphone ownership and demand for data plans have both been increasing in recent years(54), making this a viable option for similar studies in the future.

\section{Conclusions}

These results suggest that demography and activity are important drivers of mobility, influencing how scientists should quantify geographic accessibility to resources such as health facilities. Because different types of mobility manifest in different ways and occur with various frequencies, data such as GPS and survey data could be used to quantify mobility for specific types of activities, taking into account the advantages of each. Since healthcare-related mobility was particularly time-consuming and appears to be linked to several demographic characteristics in our small study, further research in this area could shed light on how people from different demographic and socioeconomic contexts access healthcare and therefore help to improve access in low-income settings.

\section{Acknowledgements}

The authors are grateful to the county commissioner, the chiefs, assistant chiefs and village elders of Busia County, Kenya for facilitating the fieldwork. We would also like to thank the people of Busia County, Kenya for participating in the study. 


\section{References}

385

386

387

388

389

390

391

392

393

394

395

396

397

398

399

400

401

402

403

404

405

406

407

408

409

410

411

412

413

414

415

416

417

418

419

420

421

422

423

424

425

1. Wesolowski A, Eagle N, Tatem AJ, Smith DL, Noor AM, Snow RW, Buckee CO. Quantifying the Impact of Human Mobility on Malaria. Science (80- ). 2012 Oct 12;338(6104):267-70.

2. Prothero RM. Disease and Mobility: A Neglected Factor in Epidemiology. Int J Epidemiol. 1977 Sep 1;6(3):259-67.

3. Bajardi P, Poletto C, Ramasco JJ, Tizzoni M, Colizza V, Vespignani A. Human Mobility Networks, Travel Restrictions, and the Global Spread of 2009 H1N1 Pandemic. Perc M, editor. PLoS One. 2011 Jan 31;6(1):e16591.

4. Pearce J, Witten K, Hiscock R, Blakely T. Regional and Urban-Rural Variations in the Association of Neighbourhood Deprivation with Community Resource Access: A National Study. Environ Plan A Econ Sp. 2008 Oct 1;40(10):2469-89.

5. Alegana VA, Maina J, Ouma PO, Macharia PM, Wright J, Atkinson PM, Okiro EA, Snow RW, Tatem AJ. National and sub-national variation in patterns of febrile case management in sub-Saharan Africa. Nat Commun. 2018 Dec 26;9(1):4994.

6. Macintyre S, Maciver S, Sooman A, Anderson A, Blane D, Ecob R, Ford G, Forsyth A, Green G, Kelly M, Mullen K, Phillimore P, Wight D. Area, Class and Health: Should we be Focusing on Places or People?*. NETSCC, on. 2019;22:213-34.

7. Chamberlin J, Jayne TS. Unpacking the Meaning of 'Market Access': Evidence from Rural Kenya. World Dev. 2013 Jan 1;41:245-64.

8. Whittington $\mathrm{D}, \mathrm{Mu} \mathrm{X}$, Roche R. Calculating the value of time spent collecting water: Some estimates for Ukunda, Kenya. World Dev. 1990 Feb 1;18(2):269-80.

9. Cook J, Kimuyu P, Whittington D. The costs of coping with poor water supply in rural Kenya. Water Resour Res. 2016;52(2):619-1539.

10. Noor AM, Zurovac D, Hay SI, Ochola SA, Snow RW. Defining equity in physical access to clinical services using geographical information systems as part of malaria planning and monitoring in Kenya. Trop Med Int Heal. 2003 Oct 1;8(10):917-26.

11. Ruktanonchai CW, Ruktanonchai NW, Nove A, Lopes S, Pezzulo C, Bosco C, Alegana VA, Burgert CR, Ayiko R, Charles AS, Lambert N, Msechu E, Kathini E, Matthews Z, Tatem AJ. Equality in Maternal and Newborn Health: Modelling Geographic Disparities in Utilisation of Care in Five East African Countries. Ali M, editor. PLoS One. 2016 Aug 25;11(8):e0162006.

12. Noor A., Gikandi P., Hay S., Muga R., Snow R. Creating spatially defined databases for equitable health service planning in low-income countries: the example of Kenya. Acta Trop. 2004 Aug 1;91(3):239-51.

13. Alegana VA, Wright JA, Pentrina U, Noor AM, Snow RW, Atkinson PM. Spatial modelling of healthcare utilisation for treatment of fever in Namibia. Int J Health Geogr. 2012 Feb 15;11(1):6.

14. Kenya Ministry of Medical Services and Ministry of Public Health \& Sanitation. HEALTH SECTOR STRATEGIC AND INVESTMENT PLAN (KHSSP) [Internet]. 2013. 
426 15. Tanser F, Gijsbertsen B, Herbst K. Modelling and understanding primary health care

427

428

429

430

431

432

433

434

435

436

437

438

439

440

441

442

443

444

445

446

447

448

449

450

451

452

453

454

455

456

457

458

459

460

461

462

463

464

465

466

467

468

469

470

471 accessibility and utilization in rural South Africa: An exploration using a geographical information system. Soc Sci Med. 2006 Aug 1;63(3):691-705.

16. Airey T. The impact of road construction on the spatial characteristics of hospital utilization in the Meru district of Kenya. Soc Sci Med. 1992 May 1;34(10):1135-46.

17. Mwabu GM. Health care decisions at the household level: Results of a rural health survey in Kenya. Soc Sci Med [Internet]. 1986;

18. Mwabu G, Mwanzia J, Liambila W. User charges in government health facilities in Kenya: effect on attendance and revenue. Health Policy Plan. 1995 Jun 1;10(2):164-70.

19. Perkins TA, Garcia AJ, Paz-Soldan VA, Stoddard ST, Reiner RC, Vazquez-Prokopec G, Bisanzio D, Morrison AC, Halsey ES, Kochel TJ, Smith DL, Kitron U, Scott TW, Tatem AJ. Theory and data for simulating fine-scale human movement in an urban environment. J R Soc Interface. 2014 Aug 20;11(99):20140642-20140642.

20. Molyneux CS, Mung'ala-Odera V, Harpham T, Snow RW. Maternal responses to childhood fevers: a comparison of rural and urban residents in coastal Kenya. Trop Med Int Heal. 1999 Dec 1;4(12):836-45.

21. Schröder L, Flägel K, Goetz K, Steinhäuser J. Mobility concepts and access to health care in a rural district in Germany: a mixed methods approach. BMC Fam Pract. 2018 May 2;19(1):47.

22. Kanuganti S, Sarkar AK, Singh AP, Arkatkar SS. Quantification of accessibility to health facilities in rural areas. Case Stud Transp Policy. 2015 Sep 1;3(3):311-20.

23. Wesolowski A, Stresman G, Eagle N, Stevenson J, Owaga C, Marube E, Bousema T, Drakeley C, Cox J, Buckee CO. Quantifying travel behavior for infectious disease research: a comparison of data from surveys and mobile phones. Sci Rep. 2015 May 14;4(1):5678.

24. Searle KM, Lubinda J, Hamapumbu H, Shields TM, Curriero FC, Smith DL, Thuma PE, Moss WJ. Characterizing and quantifying human movement patterns using GPS data loggers in an area approaching malaria elimination in rural southern Zambia. R Soc Open Sci. 2017 May 3;4(5):170046.

25. Vazquez-Prokopec GM, Bisanzio D, Stoddard ST, Paz-Soldan V, Morrison AC, Elder JP, Ramirez-Paredes J, Halsey ES, Kochel TJ, Scott TW, Kitron U. Using GPS technology to quantify human mobility, dynamic contacts and infectious disease dynamics in a resourcepoor urban environment. PLoS One. 2013 Jan 8;8(4):e58802.

26. Parsons MB, Gillespie TR, Lonsdorf E V, Travis D, Lipende I, Gilagiza B, Kamenya S, Pintea L, Vazquez-Prokopec GM. Global positioning system data-loggers: a tool to quantify fine-scale movement of domestic animals to evaluate potential for zoonotic transmission to an endangered wildlife population. PLoS One [Internet]. 2014 Jan;9(11):e110984.

27. Browning E, Bolton M, Owen E, Shoji A, Guilford T, Freeman R. Predicting animal behaviour using deep learning: GPS data alone accurately predict diving in seabirds. McPherson J, editor. Methods Ecol Evol. 2018 Mar 1;9(3):681-92.

28. Ryan PG, Petersen SL, Peters G, Gremillet D. GPS tracking a marine predator: the effects of precision, resolution and sampling rate on foraging tracks of African Penguins. Mar Biol. 2004 Aug 10;145(2):215-23.

29. Moritz M, Galehouse Z, Hao Q, Garabed RB. Can One Animal Represent an Entire Herd? Modeling Pastoral Mobility Using GPS/GIS Technology.

Peer) reviewing PDF | (2019:06:38955:1:2:NEW 16 Jan 2020) 
472 30. Siedner MJ, Lankowski A, Tsai AC, Muzoora C, Martin JN, Hunt PW, Haberer JE,

473

474

475

476

477

478

479

480

481

482

483

484

485

486

487

488

489

490

491

492

493

494

495

496

497

498

499

500

501

502

503

504

505

506

507

508

509

510

511

512

513

514

515

516

517

Bangsberg DR. GPS-measured distance to clinic, but not self-reported transportation factors, are associated with missed HIV clinic visits in rural Uganda. AIDS. 2013 Jun 1;27(9):1503-8.

31. Kenya National Bureau of Statistics. Busia County Statistical Abstract [Internet]. 2017.

32. Statistics KNB of, Health/Kenya M of, Council/Kenya NAC, Institute KMR, Development/Kenya NC for P and. Kenya Demographic and Health Survey 2014 [Internet]. 2015 [cited 2018 Feb 22].

33. QGIS Development Team. QGIS Geographic Information System. Open Source Geospatial Foundation Project.; 2019.

34. Fèvre EM, de Glanville WA, Thomas LF, Cook EAJ, Kariuki S, Wamae CN. An integrated study of human and animal infectious disease in the Lake Victoria crescent small-holder crop-livestock production system, Kenya. BMC Infect Dis. 2017 Dec 30;17(1):457.

35. Floyd JR, Ruktanonchai NW, Wardrop N, Tatem AJ, Ogola J, Fèvre EM. Exploring finescale human and livestock movement in western Kenya. One Heal [Internet]. 2019;7.

36. Kenya | PPI [Internet]. Poverty Probability Index. 2011.

37. Brunette W, Sundt M, Dell N, Chaudhri R, Breit N, Borriello G. Open data kit 2.0. In: Proceedings of the 14th Workshop on Mobile Computing Systems and Applications HotMobile '13. New York, New York, USA: ACM Press; 2013. p. 1.

38. i-gotU GT-600 GPS logger [Internet]. Taiwan: Mobile Action Technology Inc.; 2018.

39. Bohte W, Maat K. Deriving and validating trip purposes and travel modes for multi-day GPS-based travel surveys: A large-scale application in the Netherlands. Transp Res Part C Emerg Technol. 2009 Jun 1;17(3):285-97.

40. Stopher PR, Daigler V, Griffith S. Smartphone app versus GPS Logger: A comparative study. Transp Res Procedia. 2018 Jan 1;32:135-45.

41. Thuranira-McKeever C, Shaw A, Machila N, Eisler M, Welburn S, Maudlin I. Seasonal influences on livestock keeping in a sedentary crop-livestock system. Trop Anim Health Prod. 2010 Apr 7;42(4):705-17.

42. Team RC. R: A language and environment for statistical computing. [Internet]. Vienna, Austria: R Foundation for Statistical Computing; 2017.

43. Sumner MD. trip: Tools for the Analysis of Animal Track Data. R package version 1.5.0. [Internet]. 2016.

44. Noor AM, Alegana VA, Gething PW, Snow RW. A spatial national health facility database for public health sector planning in Kenya in 2008. Int J Health Geogr. 2009 Mar 6;8(1):13.

45. Wardrop NA, Thomas LF, Cook EAJ, de Glanville WA, Atkinson PM, Wamae CN, Fèvre EM. The Sero-epidemiology of Coxiella burnetii in Humans and Cattle, Western Kenya: Evidence from a Cross-Sectional Study. Vinetz JM, editor. PLoS Negl Trop Dis. 2016 Oct 7;10(10): 0005032.

46. Clark GL, Gertler MS, Feldman MP. The Oxford handbook of economic geography [Internet]. Oxford University Press; 2003. 742 p.

47. Okwi PO, Ndeng'e C G, Kristjanson P, Arunga M, Notenbaert A, Omolo A, Henninger N, Benson T, Kariuki P, Owuor J. Spatial determinants of poverty in rural Kenya [Internet]. 2007.

48. Moïsi JC, Gatakaa H, Noor AM, Williams TN, Bauni E, Tsofa B, Levine OS, Scott JAG.

Peer) reviewing PDF | (2019:06:38955:1:2:NEW 16 Jan 2020) 
518 Geographic access to care is not a determinant of child mortality in a rural Kenyan setting

49. M P, M B, JC T. Womens agricultural work child care and infant diarrhea in Rural Kenya. 50. Thaddeus' S, Maine D. Too far to walk: Maternal Mortality in context [Internet]. Vol. 38, Sm. Sci. Med. 1994.

51. Mason L, Dellicour S, Ter Kuile F, Ouma P, Phillips-Howard P, Were F, Laserson K, Desai M. Barriers and facilitators to antenatal and delivery care in western Kenya: a qualitative study. BMC Pregnancy Childbirth. 2015 Dec 13;15(1):26.

52. Mubyazi GM, Bloch P, Magnussen P, Olsen ØE, Byskov J, Hansen KS, Bygbjerg IC. Women's experiences and views about costs of seeking malaria chemoprevention and other antenatal services: a qualitative study from two districts in rural Tanzania. Malar J. 2010 Dec 17;9(1):54.

53. Ruktanonchai NW, Ruktanonchai CW, Floyd JR, Tatem AJ. Using Google Location History data to quantify fine-scale human mobility. Int J Health Geogr [Internet]. 2018;17(1).

54. World Bank. The transformational use of information and communication technologies in Africa [Internet]. 2012. 


\section{Table 1 (on next page)}

Individual and household characteristics of sample population

* PPI Kenya: Poverty Probability Index for Kenya 2011 [36]. 


\begin{tabular}{lll}
\hline Demographic covariates & $\begin{array}{l}\text { Number of participants: } \\
\text { Survey \& GPS }\end{array}$ & $\begin{array}{l}\text { Number of participants: } \\
\text { GPS only }\end{array}$ \\
\hline $\begin{array}{l}\text { Gender } \\
\text { Male }\end{array}$ & $33(43.4 \%)$ & $18(69.2 \%)$ \\
Female & $43(56.6 \%)$ & $8(30.8 \%)$ \\
\hline Age & 22 & 7 \\
$18-29$ & 26 & 8 \\
$30-49$ & 23 & 7 \\
$50-69$ & 5 & 4 \\
$70+$ & & \\
\hline Main occupation & 45 & 18 \\
Farming/agriculture & 2 & 2 \\
Hunting & 3 & 1 \\
Trading & 18 & 4 \\
Other & 8 & 1 \\
Unemployed & & \\
\hline Relative wealth score (PPI Kenya*) of participant's & & 9 \\
household & 16 & 9 \\
Less than 30 & 24 & 8 \\
30 to 50 & 12 & 6 \\
51 or more & 12 & 20 \\
\hline Ruminant ownership of participant's household & 10 & \\
No ruminants & 40 & \\
Ruminants & & \\
\hline & & \\
\hline
\end{tabular}




\section{Table 2 (on next page)}

Relationships between movement metrics and demographic characteristics of the surveyed population for different types of activity.

Univariable analysis of movement metrics using beta regression in a linear mixed model.

Estimates are given with $95 \%$ confidence intervals in square brackets. ${ }^{* * *} p<0.001,{ }^{* *} p<$ $0.01, * p<0.05$. 
1

\begin{tabular}{|c|c|c|c|c|}
\hline \multicolumn{2}{|c|}{ Activity type } & \multirow{2}{*}{$\begin{array}{l}\text { Explanatory variable } \\
\text { Gender: male }[\text { Ref = female] }\end{array}$} & \multirow{2}{*}{$\begin{array}{l}\text { Estimate } \\
15.78[2.10, \\
109.68]\end{array}$} & \multirow{2}{*}{$\begin{array}{l}\text { p-value } \\
0.007^{* *}\end{array}$} \\
\hline \multirow{8}{*}{$\begin{array}{l}\text { Livestock } \\
\text { activity }\end{array}$} & \multirow{4}{*}{ Visits per week } & & & \\
\hline & & $\begin{array}{l}\text { Occupation: non-farmer [Ref = } \\
\text { farmer] }\end{array}$ & $0.08[0.01,0.65]$ & $0.022 *$ \\
\hline & & Household wealth & $0.17[0.01,3.69]$ & 0.263 \\
\hline & & Age & $1.04[0.97,1.11]$ & 0.245 \\
\hline & \multirow{4}{*}{ Time spent } & Gender: male [Ref = female] & $5.33[1.41,20.22]$ & $0.017^{*}$ \\
\hline & & $\begin{array}{l}\text { Occupation: non-farmer [Ref = } \\
\text { farmer] }\end{array}$ & $0.68[0.17,2.79]$ & 0.591 \\
\hline & & Household wealth & $5.46[0.95,31.05]$ & 0.063 \\
\hline & & Age & $1.03[0.99,1.07]$ & 0.206 \\
\hline \multirow{9}{*}{$\begin{array}{l}\text { Health } \\
\text { facility }\end{array}$} & \multirow{5}{*}{$\begin{array}{l}\text { Visits per } \\
\text { week }\end{array}$} & Gender: male $[$ Ref $=$ female $]$ & & $<0.001$ \\
\hline & & & $0.12[0.04,0.36]$ & $* * *$ \\
\hline & & $\begin{array}{l}\text { Occupation: non-farmer [Ref = } \\
\text { farmer] }\end{array}$ & $2.96[0.93,9.44]$ & 0.069 \\
\hline & & Household wealth & $0.25[0.06,1.10]$ & 0.071 \\
\hline & & Age & $0.97[0.93,1.00]$ & $0.041 *$ \\
\hline & \multirow{4}{*}{ Time spent } & Gender: male [Ref = female] & $0.65[0.46,0.92]$ & $0.019 *$ \\
\hline & & $\begin{array}{l}\text { Occupation: non-farmer [Ref = } \\
\text { farmer] }\end{array}$ & $0.88[0.60,1.28]$ & 0.504 \\
\hline & & Household wealth & $0.70[0.42,1.18]$ & 0.193 \\
\hline & & Age & $0.99[0.98,1.01]$ & 0.338 \\
\hline \multirow{8}{*}{$\begin{array}{l}\text { Place of } \\
\text { worship }\end{array}$} & \multirow{4}{*}{$\begin{array}{l}\text { Visits per } \\
\text { week }\end{array}$} & Gender: male [Ref = female] & $0.50[0.24,1.00]$ & 0.054 \\
\hline & & $\begin{array}{l}\text { Occupation: non-farmer [Ref = } \\
\text { farmer] }\end{array}$ & $1.01[0.48,2.14]$ & 0.984 \\
\hline & & Household wealth & $0.65[0.23,1.84]$ & 0.425 \\
\hline & & Age & $1.01[0.98,1.03]$ & 0.617 \\
\hline & \multirow{4}{*}{ Time spent } & Gender: male [Ref = female] & $0.81[0.65,1.00]$ & 0.051 \\
\hline & & $\begin{array}{l}\text { Occupation: non-farmer [Ref = } \\
\text { farmer] }\end{array}$ & $1.03[0.82,1.28]$ & 0.812 \\
\hline & & Household wealth & $0.72[0.54,0.96]$ & $0.032 *$ \\
\hline & & Age & $0.99[0.98,1.00]$ & $0.003 * *$ \\
\hline \multirow{5}{*}{ Market } & \multirow{4}{*}{$\begin{array}{l}\text { Visits per } \\
\text { week }\end{array}$} & Gender: male [Ref = female] & $1.09[0.37,3.09]$ & 0.875 \\
\hline & & $\begin{array}{l}\text { Occupation: non-farmer [Ref = } \\
\text { farmer] }\end{array}$ & $0.43[0.14,1.36]$ & 0.135 \\
\hline & & Household wealth & $1.29[0.27,6.13]$ & 0.753 \\
\hline & & Age & $0.97[0.95,1.00]$ & 0.121 \\
\hline & Time spent & Gender: male $[$ Ref = female] & $1.24[0.54,2.87]$ & 0.611 \\
\hline
\end{tabular}




\begin{tabular}{|c|c|c|c|c|}
\hline & & $\begin{array}{l}\text { Occupation: non-farmer [Ref = } \\
\text { farmer] }\end{array}$ & $0.64[0.28,1.47]$ & 0.299 \\
\hline & & Household wealth & $0.98[0.34,2.84]$ & 0.970 \\
\hline & & Age & $0.99[0.96,1.01]$ & 0.316 \\
\hline \multirow{8}{*}{$\begin{array}{l}\text { Household } \\
\text { visits }\end{array}$} & \multirow{4}{*}{$\begin{array}{l}\text { Visits per } \\
\text { week }\end{array}$} & Gender: male $[$ Ref $=$ female $]$ & $1.39[0.38,4.85]$ & 0.612 \\
\hline & & $\begin{array}{l}\text { Occupation: non-farmer [Ref = } \\
\text { farmer] }\end{array}$ & $0.92[0.24,3.55]$ & 0.909 \\
\hline & & Household wealth & $1.12[0.16,7.49]$ & 0.908 \\
\hline & & Age & $0.97[0.93,1.01]$ & 0.122 \\
\hline & \multirow{4}{*}{ Time spent } & Gender: male [Ref = female] & $1.22[0.78,1.93]$ & 0.387 \\
\hline & & $\begin{array}{l}\text { Occupation: non-farmer }[\text { Ref }= \\
\text { farmer] }\end{array}$ & $0.83[0.51,1.33]$ & 0.438 \\
\hline & & Household wealth & $0.87[0.46,1.62]$ & 0.655 \\
\hline & & Age & $1.00[0.98,1.01]$ & 0.663 \\
\hline \multirow{10}{*}{$\begin{array}{l}\text { Water } \\
\text { activity }\end{array}$} & \multirow{6}{*}{$\begin{array}{l}\text { Visits per } \\
\text { week }\end{array}$} & Gender: male [Ref = female] & & $<0.001$ \\
\hline & & & $0.02[0.00,0.12]$ & $* * *$ \\
\hline & & $\begin{array}{l}\text { Occupation: non-farmer [Ref = } \\
\text { farmer] }\end{array}$ & $4.80[0.47,49.31]$ & 0.191 \\
\hline & & Household wealth & $0.10[0.00,2.66]$ & 0.176 \\
\hline & & Age & & $<0.001$ \\
\hline & & & $0.87[0.81,0.92]$ & $* * *$ \\
\hline & \multirow{4}{*}{ Time spent } & Gender: male [Ref = female] & $2.52[0.92,6.65]$ & 0.075 \\
\hline & & $\begin{array}{l}\text { Occupation: non-farmer [Ref = } \\
\text { farmer] }\end{array}$ & $0.86[0.34,2.13]$ & 0.755 \\
\hline & & Household wealth & $0.69[0.22,2.17]$ & 0.535 \\
\hline & & Age & $1.00[0.97,1.03]$ & 0.976 \\
\hline
\end{tabular}


Figure 1

Map of the study area.

(A) Kenya with Busia county highlighted in yellow. (B) Busia county with the 11 selected sublocations highlighted in red.

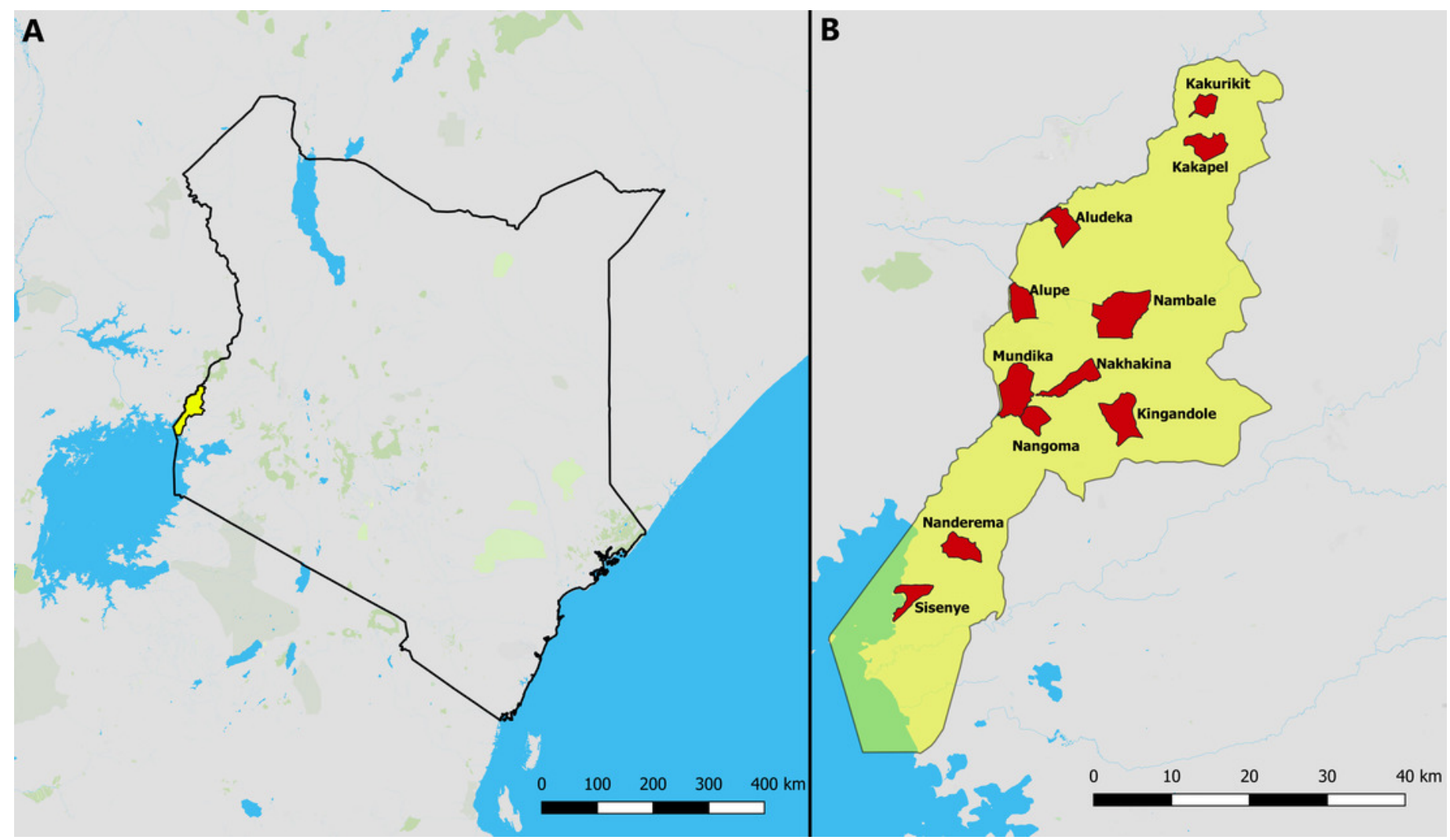


Figure 2

Frequencies of visits to different types of places.
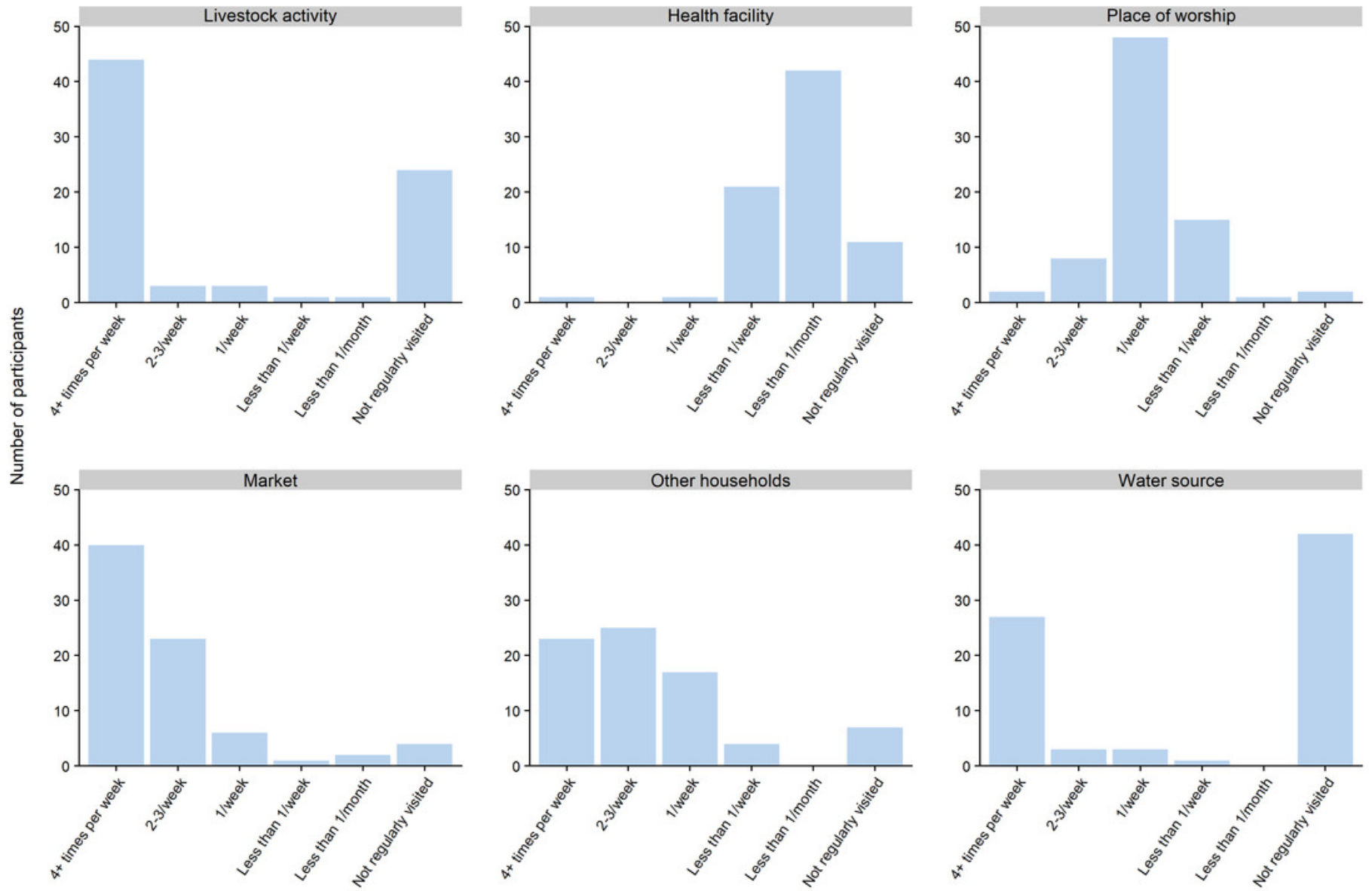

Frequency of visits 
Figure 3

Time spent travelling one-way to different types of places.
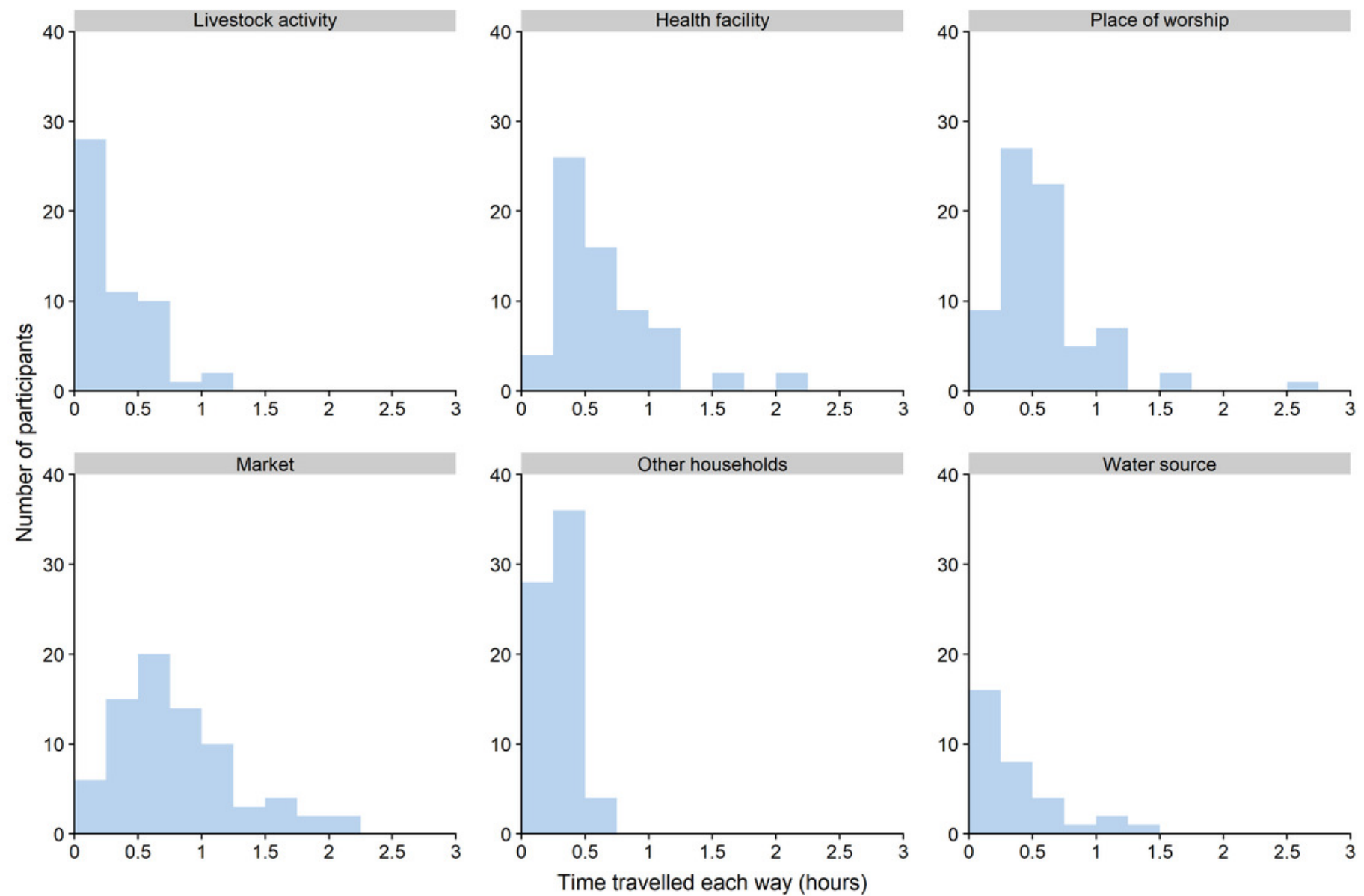
Figure 4

Time spent by participants at different types of places.
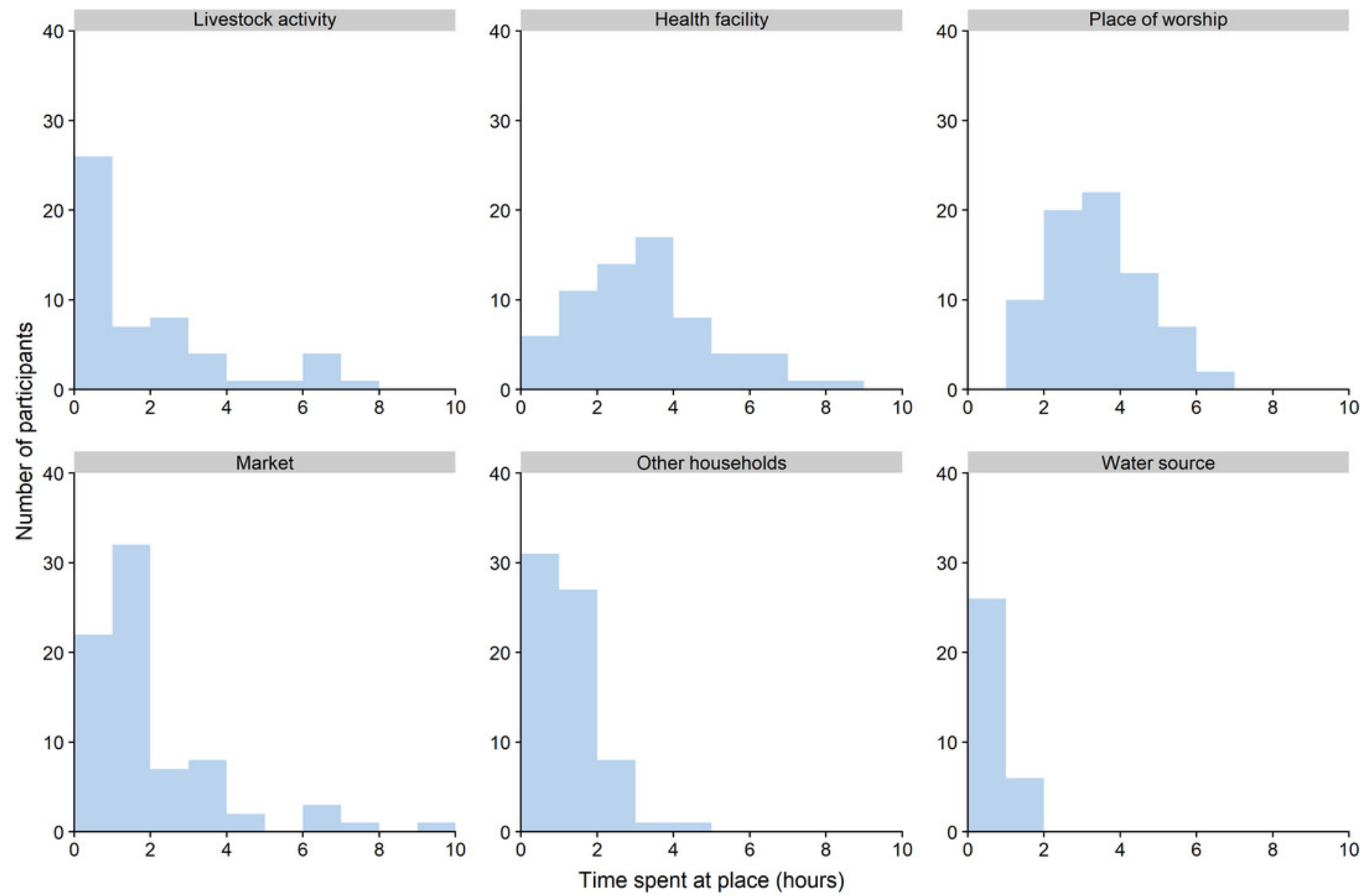
Figure 5

Network representation of mean proportions of time spent in different types of places.

Mean proportions of time spent from GPS (orange) and survey (blue) data.

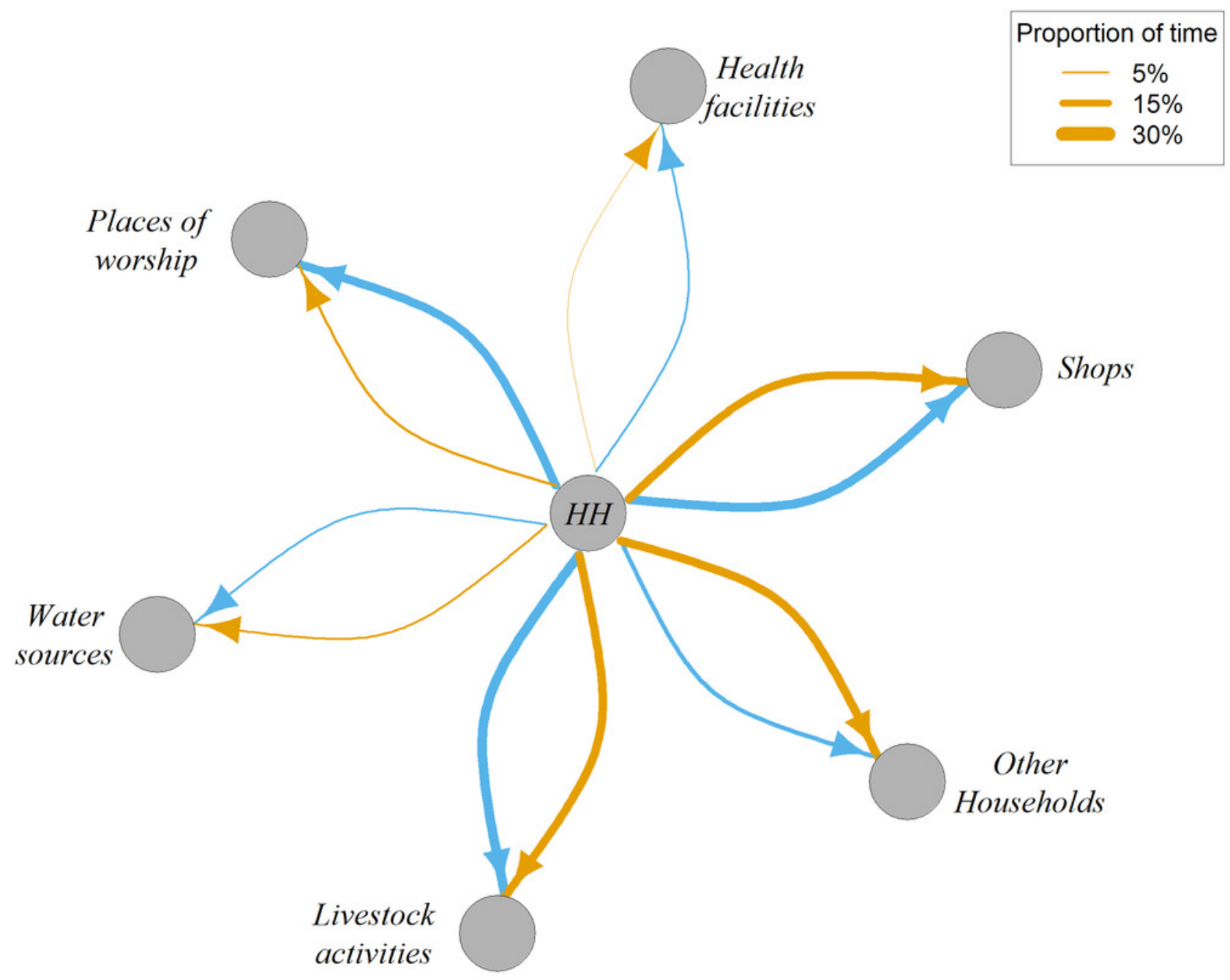

